\title{
Self-motivated medical care-seeking behaviors and disease progression in a community-based cohort of chronic hepatitis B virus-infected patients in China
}

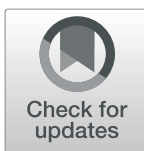

Hui Zheng ${ }^{1 \dagger}$, Guomin Zhang ${ }^{1 \dagger}$, Fuzhen Wang ${ }^{1 \dagger}$, Zundong Yin ${ }^{1}$, Ning Miao ${ }^{1}$, Xiaojin Sun ${ }^{1}$, Xiaofeng Liang ${ }^{1 *}$ and Fuqiang Cui ${ }^{*}$ (D)

\begin{abstract}
Background: To determine the treatment behaviors among a community-based cohort of chronic hepatitis B virus (HBV)-infected persons and to examine the disease progression among non-antiviral-treated HBV-infected cases after 5 years of follow-up.

Methods: We conducted a community-based prospective study on people with chronic HBV infection in mainland China from 2009 to 2014. In 2009, we recruited participants who were identified as HBV infected in 2006 in a national sero-survey. A face-to-face follow-up investigation was completed in 2014, and the personal information, the clinical diagnosis provided at the last hospital visit, the HBV antiviral treatment history, and the insurance type was collected for each patient for analysis. Multivariable logistic regression was used to identify factors that are associated with active medical care- seeking and antiviral treatments.

Results: Among the 2422 chronic HBV-infected patients recruited in 2009, 1784 (73.7\%) were followed-up to 2014, and 638 (35.8\%) had sought medical care in hospitals; among them, 140 (21.9\%) received antiviral treatments. The lowest medical care-seeking rate (26\%) was in participants over 50-year old. We determined that the frequency of medical

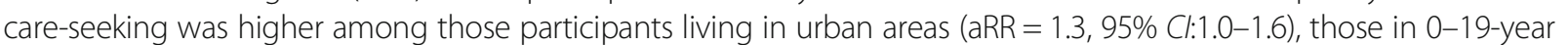
old ( $\mathrm{aRR}=1.5,95 \% \mathrm{Cl}: 1.1-2.1)$, 20-39-year old ( $\mathrm{aRR}=2.2,95 \% \mathrm{Cl}: 1.7-3.0)$ and 40-49-year old ( $\mathrm{aRR}=1.5,95 \% \mathrm{Cl}: 1.1-2.0$ ), and persons with insurance of the type Urban residents' basic medical insurance (URBMI) or Commercial health insurance (CHI) (aRR $=2.5,95 \%$ Cl:1.7-3.6) and New Rural Cooperative Medical System (NRCMS) (aRR = 1.9, 95\% Cl:1.42.6). Patients were more likely to receive antiviral treatment if they were 20-39-year old (aRR $=0.4,95 \%$ Cl:0.3-0.7), had insurance of the type URBMI or CHI (aRR $=2.6$, 95\% Cl:1.1-6.3) or NRCMS (aRR $=3.0,95 \%$ Cl:1.3-6.9) and were treated at prefecture and above-level hospitals (aRR $=2.0,95 \%$ Cl:1.4-3.0). Among non-antiviral-treated HBV-infected cases, we found the annual rates for HBsAg sero-clearance, progress to cirrhosis and HCC were 1.0, 0.6 and $0.2 \%$, respectively.

Conclusion: The rates of medical care-seeking and antiviral treatment were low among community-based chronic HBV-infected persons, thus we recommend improving the insurance policies for HBV-infected persons to increase the antiviral treatment rate, and conducting extensive education to promote HBV-infected patients actively seeking medical care from hospitals.
\end{abstract}

Keywords: Hepatitis B, Chronic infection, Medical care behaviors

\footnotetext{
* Correspondence: liangxf@chinacdc.cn; nip2018@163.com

${ }^{\dagger}$ Hui Zheng, Guomin Zhang and Fuzhen Wang contributed equally to this work.

${ }^{1}$ National Immunization Program, Chinese Center for Disease Control and Prevention, Beijing, China

${ }^{2}$ Department of Laboratorial Science and Technology \& Vaccine Research Center, School of Public Health, Peking University, Beijing, China
}

(c) The Author(s). 2019 Open Access This article is distributed under the terms of the Creative Commons Attribution 4.0 International License (http://creativecommons.org/licenses/by/4.0/), which permits unrestricted use, distribution, and reproduction in any medium, provided you give appropriate credit to the original author(s) and the source, provide a link to the Creative Commons license, and indicate if changes were made. The Creative Commons Public Domain Dedication waiver (http://creativecommons.org/publicdomain/zero/1.0/) applies to the data made available in this article, unless otherwise stated. 


\section{Background}

Chronic viral hepatitis is a major threat to public health worldwide, with nearly 257-million people living with chronic hepatitis B virus (HBV) infection [1]. Carriers of $\mathrm{HBV}$ are at increased risk for hepatocellular carcinoma (HCC) and end-stage liver diseases [2, 3]. Approximately 600-thousand to 1-million people die every year from these serious consequences of HBV infection [2]. The WHO advocates the adoption of an expanded and accelerated action to reduce the HBV burden and to eliminate $\mathrm{HBV}$ as a great public threat by 2030 [4]. Growing evidence has shown that antiviral therapy is effective and can reduce the risk of HCC development in chronic hepatitis $\mathrm{B}(\mathrm{CHB})$; hence, early diagnosis of and antiviral treatment for $\mathrm{CHB}$ are crucial for reducing morbidity and mortality [5-8].

In China, despite the success of neonatal vaccination since 1992, which has achieved a $97 \%$ reduction in the HBsAg seroprevalence from $9.7 \%$ in 1992 to $0.32 \%$ in 2014 among children under 5 years old $[9,10]$, there are still great challenges; nearly 90 -million people living with HBV infection [11]. Recent surveillance data show HCC to be ranked as the third leading cause of cancer-related deaths in China, and $80-85 \%$ of those deaths are caused by HBV infection [12-14]. This heavy HBV-related disease burden is a cause for great concern, and it is expected that the death rate from HBV infection will continue to increase if no actions are taken. Therefore, there is a need for a comprehensive strategy for the control and prevention of hepatitis $B$ that goes beyond vaccination and includes the early detection and treatment of chronic hepatitis B as key elements.

Numerous studies from China have demonstrated a successful vaccination history in reducing the HBsAg prevalence from 1979 to 2014 [10, 11, 15]. There are fewer available data regarding community-based chronic HBVinfected persons who need medical care and treatment, estimating the resources needed for rendering medical service to them. Furthermore, most previous studies on the medical behaviors of HBV-infected persons or the antiviral treatment analysis thereof were focused on the hospitalbased populations [16-19]; very few related studies have been conducted on community-based populations.

We designed and conducted a prospective study on community-basedHBV-infected persons to analyze their medical care-seeking behaviors and their antiviral treatment situation, as well as the related factors; for HBVinfected cases without anti-viral treatment, we observed the disease progression after a 5-year follow-up.

\section{Methods}

\section{Cohort establishment and study design}

We performed a community-based prospective followup study on a chronic HBV-infected cohort to observe their self-motivated medical care-seeking behaviors. In 2009, we revisited the chronic HBV-infected persons who were shown to be HBsAg-positive in a 2006 national sero-survey that employed a multistage random sampling method [9], and then we recruited target subjects with the following inclusion criteria: 1) reliable HBsAg-positive test results; 2) local resident for at least 6 months; 3) no other chronic liver diseases, such as coinfection with hepatitis $\mathrm{C}$ virus ( $\mathrm{HCV}$ ) or hepatitis D virus (HDV), alcoholic or nonalcoholic fatty liver disease or steatohepatitis; 4) willingness to participate in the investigation.

\section{Diagnostic criteria for HBV infection}

Each participant was clinically examined for any signs and symptoms of liver disease, after which routine blood tests, including alanine transaminase (ALT), and an abdominal ultrasound were performed. According to the national guidelines $[20,21]$, hepatitis B patients should be classified as follows: (1) carrier: HBsAg-positive cases with no symptoms of liver diseases (e.g., nausea, vomiting, diarrhea, anorexia, abdominal pain, and jaundice) and normal ALT levels $(\leq 40 \mathrm{IU} / \mathrm{mL})$; (2) CHB: HBsAg-positive cases with abnormal ALT levels $(>80 \mathrm{IU} / \mathrm{mL})$ and at least one of the following: $\mathrm{HBV}$ infection $\geq 6$ months prior, chronic inflammatory changes reported on abdominal ultrasound, or anti-HBc IgM negative; (3) liver cirrhosis (LC): HBsAg-positive cases with liver cirrhosis as reported via abdominal ultrasound, computerized tomography (CT) or Magnetic Resonance Imaging (MRI); (4) HCC: cases with liver lesion(s) suggestive of hepatocellular carcinoma reported via abdominal ultrasound, CT or MRI together with alpha fetoprotein (AFP) $>400 \mu \mathrm{g} / \mathrm{mL}$; and (5) HBsAg sero-clearance: cases with HBsAg changing from positive to negative, positive or negative for anti-HBs.

\section{Follow-up investigation and data collection}

We conducted face-to-face follow-up appointments in 2014, and data were collected by trained staff in 2014 . We collected the primary information on medical care behaviors and disease progression and reviewed the case information according to the above mentioned criteria. The data included personal information, the clinical diagnosis at the last visit, which was provided by the hospital, the antiviral treatment history (including Tenofovir, Entecavir, Adefovir, Lamivudine, and PEG-IFN), and the insurance status. The patients were classified as having self-motivated medical care behavior for HBVrelated diseases by providing related evidence during the study period, such as hospital diagnostic records, prescriptions or hospital testing results. 


\section{Quality control}

In 2009, for each participant, the clinical diagnosis was reconfirmed by national hepatitis clinical experts. Regular communications were conducted to reduce the loss to follow-up. In 2014, we used a unified questionnaire to investigate the medical care-seeking behaviors; the questionnaire was administered by trained staff, and the subsequent clinical diagnosis and the treatment history were demonstrated by obtaining copies of the hospitals' documents.

\section{Statistical analysis}

All the data were double-entered using EPI Data 3.1 (EPI Data Association, Odense, Denmark) and checked for consistency. We used SPSS software (version 23, IBM, United States) and SAS software (version 9.4, SAS Institute, Inc., Cary, NC, USA) for the statistical analyses. Descriptive statistical methods were used to analyze the demographic characteristics and the proportion of disease status among HBV-infected persons. The chi-square test and multivariate regression analyses [presented as the relative risk (RR) with $95 \%$ confidence intervals $(C I)]$ were used to compare the risk factors related to the active medical care-seeking behaviors and antiviral treatments of HBV-infected persons. The estimation of the rates of disease progression and $\mathrm{HBsAg}$ sero-clearance were calculated by a person-year using the life table method. Statistical significance was considered for those results with a two-tailed $p<0.05$.

\section{Ethical issues}

This study was approved by the China CDC Ethical Review Committee, and the study was conducted following the ethics regulations. All participants were informed of the study purpose and their right to keep information confidential.

\section{Results}

A total of 2422 hepatitis B virus-infected patients were enrolled from 31 provinces in China in 2009 (Fig. 1); the demographic characteristics of the cohort are shown in Table 1. Among the participants, 1784 (74\%) were followed up to 2014. No significant differences were detected between followed-up persons and lost to followup (LTFU) persons in terms of gender $(P=0.27)$ and area of residence (rural or urban) $(P=0.16)$ (Fig. 2), Table 1).

In 2009, we confirmed that $1550(64 \%)$ of the participants were HBV carriers, 839 (34.6\%) had CHB, 29 (1.2\%) had LC and $4(0.2 \%)$ had HCC. Significant differences in HBV infection status existed among age-groups $(P<0.001)$ and regions $(P<0.001)$. All the HCC cases and nearly two-thirds of the LC cases occurred in rural areas (Table 1).
In 2014, 64.2\% (1146/1784) of the follow-ups had not visited a clinic. Among the 638 participants who had actively sought medical care, $433(67.9 \%)$ received a medical examination but no medication, 65 (10.2\%) took Chinese traditional herbal medicine, and there were 140 (21.9\%) cases who received antiviral treatment (Table 2). The participants' self-reported reasons for not visiting a hospital included the following: 1) 92.8\% (1063/1164) claimed not to experience any liver disease symptoms; 2 ) $10.0 \%(115 / 1164)$ indicated that the hospital cost was high; and 3) 6.3\% (76/1164) were concerned about their privacy.

In our bivariate analysis, we detected significant differences in both the active medical care-seeking behaviors and antiviral treatments of chronic HBV-infected persons according to age-group and insurance type. In addition, significant differences were detected the active medical care-seeking behaviors of chronic HBV-infected persons according to region and living in a rural vs urban area (all $p$-values <0.05) (Table 3 ). In the multivariable analysis, participants were more likely to actively seek medical care if they were urban $(\mathrm{aRR}=1.3$, 95\% CI:1.0-1.6), 0-19 years old (aRR $=1.5$, 95\% CI:1.12.1), 20-39 years old $(\mathrm{aRR}=2.2$, 95\% CI:1.7-3.0) 40-49 years old $(\mathrm{aRR}=1.5,95 \%$ CI:1.1-2.0), with insurance of Urban residents' basic medical insurance (URBMI) or Commercial health insurance (CHI) $(\mathrm{aRR}=2.5,95 \% \mathrm{CI}$ : 1.7-3.6) and New Rural Cooperative Medical System (NRCMS) (aRR $=1.9,95 \%$ CI:1.4-2.6). In addition, patients were more likely to receive antiviral treatments if they were $20-39$ years old ( $\mathrm{aRR}=0.4,95 \%$ CI:0.3-0.7), with insurance of URBMI or CHI $(\mathrm{aRR}=2.6,95 \% \mathrm{CI}$ : 1.1-6.3) and NRCMS (aRR = 3.0, 95\% CI:1.3-6.9) and if they were treated at a prefecture and above-level hospital (aRR $=2.0,95 \%$ CI:1.4-3.0) (Table 3).

We analyzed the natural disease progression among 370 chronic hepatitis B patients who did not accept any antiviral therapy. During 1212 person-years of follow-up, the annual rates for $\mathrm{HBsAg}$ sero-clearance, progress to cirrhosis and HCC were 1.0, 0.6 and $0.2 \%$, respectively (Table 4).

Among the carriers, we determined that 11 persons had HBsAg sero-clearance, and 56 persons progressed to $\mathrm{CHB}$ during 821 person-years of followup, making the annual rate of sero-clearance and $\mathrm{CHB} 1.3$ and 6.8\%, respectively. Among the $\mathrm{CHB}$ participants, only one person had HBsAg seroclearance, and two persons experienced cirrhosis after 391 person-years of follow-up, yielding annual rates of sero-clearance and cirrhosis of 0.3 and $0.5 \%$, respectively. During 29 person-years of follow-up for participants with cirrhosis, two persons developed HCC, yielding an annual probability of cirrhosis to HCC of $6.9 \%$ (Table 4). 


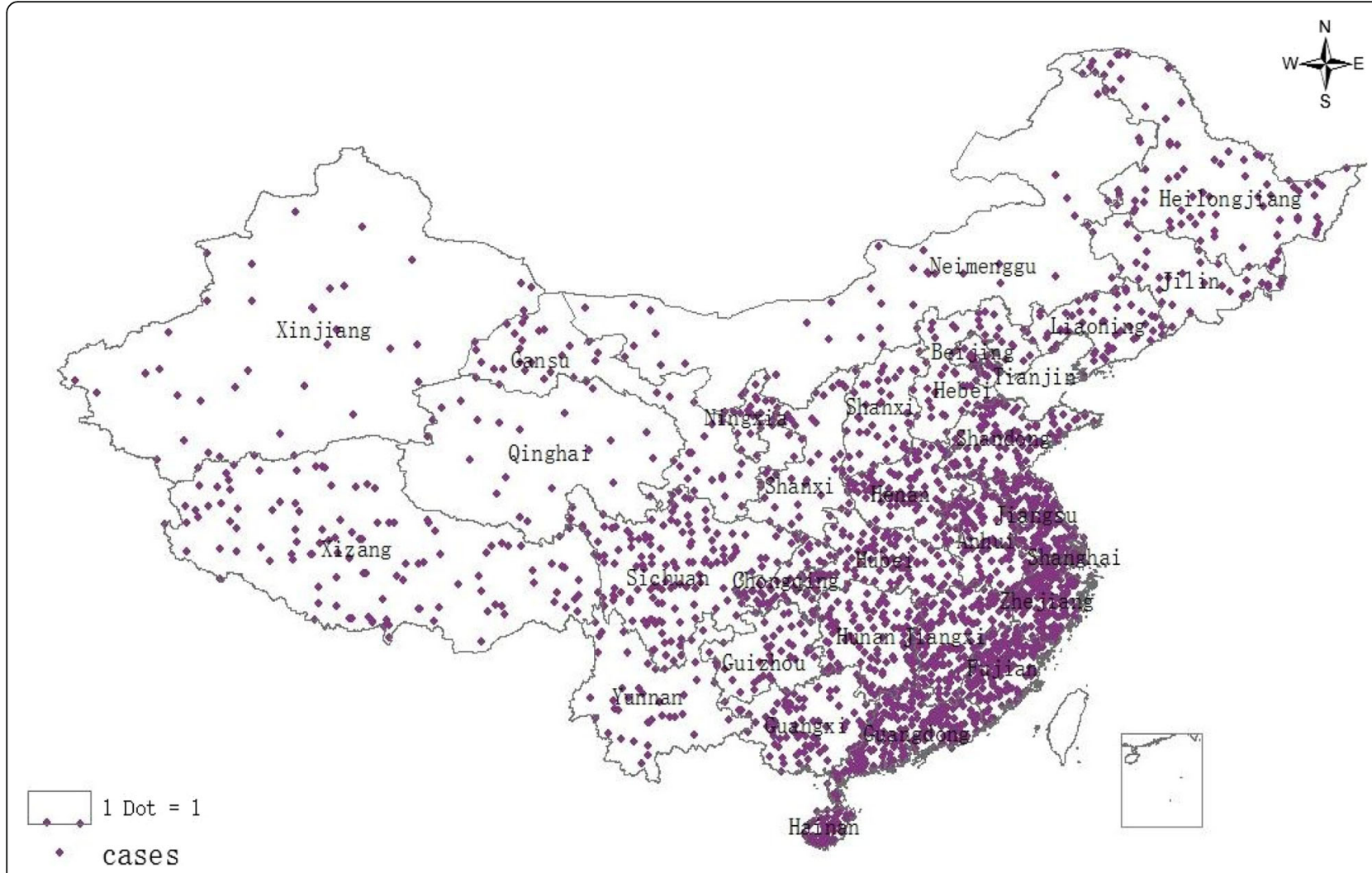

Fig. 1 Sample distribution of chronic HBV-infected cohort in China, 2009-2014

\section{Discussion}

Studies have suggested that among the 90-million HBVinfected people in China, 28-million are chronic active hepatitis B patients with symptoms who need to be treated, based on the model [11, 22-24]. In contrast, studies exploring the different disease status of communitybased HBV infected persons are limited, although such studies are the basis for the scientific estimation of the HBV burden and health resource allocation.

In this study, we identified that among $\mathrm{HBV}$-infected cases, nearly $64 \%$ were carriers and $35 \%$ had $\mathrm{CHB}$, which was a finding that was very similar to previous estimations that $\mathrm{CHB}$ would account for $1 / 3$ of HBV-infected people $[25,26]$. In China, $80-90 \%$ of the chronic HBV infections were acquired through mother-to-child transmission (MTCT) in the prevaccine era, and most of these cases were in the immune tolerance stage with normal ALT and without obvious inflammation of the liver [25]. Our results demonstrate that with increasing age, the proportions of CHB (from 23 to 40\%), LC (from 0.5 to $2.3 \%$ ) and HCC (from 0 to $0.5 \%$ ) increased, whereas the carrier proportion decreases from 76 to 57\%. In contrast, Yang SG [27] reported that the proportion of $\mathrm{CHB}$ among $\mathrm{HBsAg}$-positive persons was only $3.98 \%$ in a community-based study in Zhejiang province. The difference may be due to differences in the diagnostic criteria, as $95 \%$ of $\mathrm{HBsAg}$-positive persons were classified as HBV carriers in that study, which is much higher than is generally acknowledged. Among cases not receiving any treatment, the annual personyear HBsAg sero-clearance rate was nearly $1.0 \%$, and most of the sero-clearance occurred in asymptomatic carriers, which is similar to results from previous studies [28]. Without antiviral intervention, $0.5 \%$ of the $\mathrm{CHB}$ patients would develop cirrhosis annually; however, the progress from cirrhosis to $\mathrm{HCC}$ was nearly $7 \%$. To interrupt the progress from active chronic hepatitis $\mathrm{B}$ to cirrhosis and in turn slow the development from cirrhosis to $\mathrm{HCC}$, which is the primary target of HBV treatment, regular hospital examinations and antiviral treatment at the appropriate starting point were shown to be important.

We determined that the self-motivated clinic visitation rate is low; it was only $35 \%$, even among those who are aware they were infected with HBV. Regular medical examinations can monitor the disease, and effective measures can be taken to slow the disease progression when necessary [29]. Studies have demonstrated that people's misunderstanding of the goals and the effectiveness of treatments greatly influence the medical behaviors of HBV carriers [23, 30]. In our study, we determined that nearly $93 \%$ of persons who exhibited no self-motivated 
Table 1 The demographic characteristics of follow-up cases and lost to follow-up cases in the HBV-infected cohort, China, 2009

\begin{tabular}{|c|c|c|c|c|c|c|c|c|c|c|c|c|}
\hline \multirow{3}{*}{ Gender } & \multicolumn{4}{|c|}{ Followed-up [n, (\%)] } & \multicolumn{4}{|c|}{ Lost to follow-up [n, (\%)] } & \multicolumn{4}{|c|}{ Total [n, (\%)] } \\
\hline & Carrier & $\mathrm{CHB}^{\mathrm{a}}$ & $L C^{b}$ & $\mathrm{HCC}^{\mathrm{C}}$ & Carrier & $\mathrm{CHB}$ & LC & $\mathrm{HCC}$ & Carrier & $\mathrm{CHB}$ & LC & $\mathrm{HCC}$ \\
\hline & & & & & & & & & & & & \\
\hline \multirow[t]{2}{*}{ Male } & 633 & 318 & 15 & 1 & 184 & 139 & 5 & 1 & 817 & 457 & 20 & 2 \\
\hline & $(53.6)$ & $(55.1)$ & $(62.5)$ & $(50.0)$ & $(49.9)$ & $(53.1)$ & $(100)$ & $(50.0)$ & $(52.7)$ & $(54.5)$ & $(69.0)$ & $(50.0)$ \\
\hline \multirow[t]{2}{*}{ Female } & 548 & 259 & 9 & 1 & 185 & 123 & 0 & 1 & 733 & 382 & 9 & 2 \\
\hline & $(46.4)$ & (44.9) & (37.5) & $(50.0)$ & $(50.1)$ & (46.9) & $(0.0)$ & $(50.0)$ & $(47.3)$ & $(45.5)$ & $(31.0)$ & $(50.0)$ \\
\hline \multicolumn{13}{|l|}{ Age group } \\
\hline \multirow[t]{2}{*}{ 0-19 } & 213 & 51 & 2 & 0 & 101 & 44 & 0 & 0 & 314 & 95 & 2 & 0 \\
\hline & $(18.0)$ & $(8.8)$ & (8.3) & $(0.0)$ & $(27.4)$ & (16.8) & $(0.0)$ & $(0.0)$ & (20.3) & (11.3) & (6.9) & $(0.0)$ \\
\hline \multirow[t]{2}{*}{ 20-39 } & 400 & 184 & 4 & 0 & 121 & 84 & 0 & 0 & 521 & 268 & 4 & 0 \\
\hline & (33.9) & (31.9) & (16.7) & $(0.0)$ & (32.8) & (32.1) & $(0.0)$ & $(0.0)$ & (33.6) & (31.9) & (13.8) & $(0.0)$ \\
\hline \multirow[t]{2}{*}{$40-49$} & 322 & 179 & 8 & 1 & 64 & 67 & 2 & 0 & 386 & 246 & 10 & 1 \\
\hline & $(27.3)$ & (31.0) & (33.3) & $(50.0)$ & (17.3) & (25.6) & $(40.0)$ & $(0.0)$ & (24.9) & (29.3) & $(34.5)$ & (25.0) \\
\hline \multirow[t]{2}{*}{$50-62$} & 246 & 163 & 10 & 1 & 83 & 67 & 3 & 2 & 329 & 230 & 13 & 3 \\
\hline & $(20.8)$ & $(28.2)$ & (41.7) & $(50.0)$ & $(22.5)$ & (25.6) & $(60.0)$ & $(100.0)$ & $(21.2)$ & (27.4) & $(44.8)$ & (75.0) \\
\hline \multicolumn{13}{|l|}{ Region } \\
\hline \multirow[t]{2}{*}{ East } & 569 & 235 & 14 & 2 & 90 & 53 & 2 & 1 & 659 & 288 & 16 & 3 \\
\hline & $(48.2)$ & $(40.7)$ & (58.3) & (100) & $(22.4)$ & $(20.2)$ & $(40.0)$ & $(50.0)$ & $(42.5)$ & (34.3) & $(55.2)$ & (75.0) \\
\hline \multirow[t]{2}{*}{ Central } & 321 & 225 & 8 & 0 & 144 & 84 & 3 & 1 & 465 & 309 & 11 & 1 \\
\hline & $(27.2)$ & $(39.0)$ & (33.3) & $(0.0)$ & (39.0) & (32.1) & $(60.0)$ & $(50.0)$ & $(30.0)$ & (36.8) & (37.9) & (25.0) \\
\hline \multirow[t]{2}{*}{ West } & 291 & 117 & 2 & 0 & 135 & 125 & 0 & 0 & 426 & 242 & 2 & 0 \\
\hline & $(24.6)$ & (20.3) & (8.3) & $(0.0)$ & (36.6) & $(47.7)$ & $(0.0)$ & $(0.0)$ & $(27.5)$ & (28.8) & (6.9) & $(0.0)$ \\
\hline \multicolumn{13}{|c|}{ Rural/Urban } \\
\hline \multirow[t]{2}{*}{ Urban } & 430 & 249 & 9 & 0 & 154 & 110 & 3 & 0 & 584 & 359 & 12 & 0 \\
\hline & $(36.4)$ & $(43.2)$ & (37.5) & $(0.0)$ & $(41.7)$ & (42.0) & $(60.0)$ & $(0.0)$ & $(37.7)$ & $(42.8)$ & $(41.4)$ & $(0.0)$ \\
\hline \multirow[t]{2}{*}{ Rural } & 751 & 328 & 15 & 2 & 215 & 152 & 2 & 2 & 966 & 480 & 17 & 4 \\
\hline & (63.6) & (56.8) & (62.5) & (100) & (58.3) & (58.0) & $(40.0)$ & (100) & $(62.3)$ & $(57.2)$ & (58.6) & (100.0) \\
\hline \multirow[t]{2}{*}{ Total } & 1181 & 577 & 24 & 2 & 369 & 262 & 5 & 2 & 1550 & 839 & 29 & 4 \\
\hline & (100) & (100) & (100) & (100) & (100) & $(100)$ & $(100)$ & $(100)$ & (100) & (100) & (100) & (100) \\
\hline
\end{tabular}

${ }^{a}$ CHB chronic hepatitis B

${ }^{\mathrm{b}} \mathrm{LC}$ liver cirrhosis

c HCC hepatocellular carcinoma

medical behaviors misunderstood their symptoms and did not believe that they needed to go to the hospital, which suggests that the health education targeted at such individuals should be strengthened to promote their knowledge of the importance of regular medical examinations. In addition, $6 \%$ of the LTFUs reported fear of their HBV infection being known by others. Such data reflects that discrimination related to hepatitis $B$ exists in China [31-33] and affects people's medical behavior to some extent.

The rate of antiviral treatment for hepatitis B in China was shown to be low. According to our study, the rate of antiviral treatment among community-based HBVinfected persons was only approximately $8 \%$, which is much lower than the hospital-based estimation of 12-
$19 \%$ [34]. Based on the modeling estimation by the WHO, HBV-related mortality in China will rise continuously in the next $30-40$ years, given the present $12.5 \%$ antiviral treatment rate, unless we increase this rate to $50 \%$ of CHBs, which could greatly reduce the rate of HBV-related death for LC and HCC in 5 years [35]. Meanwhile, over-treatment also occurs. We determined that $7.5 \%$ of $\mathrm{HBV}$ carriers had taken antiviral medicine even when such treatment was unwarranted [29]. Inappropriate antiviral treatment does not have a good effect; instead, it poses an economic burden for families and wastes medical resources.

Compared to young people aged 20-39-yrs, the selfmotivated medical visitation rate was lower among those over 40-yrs old, who should be treated as priority 


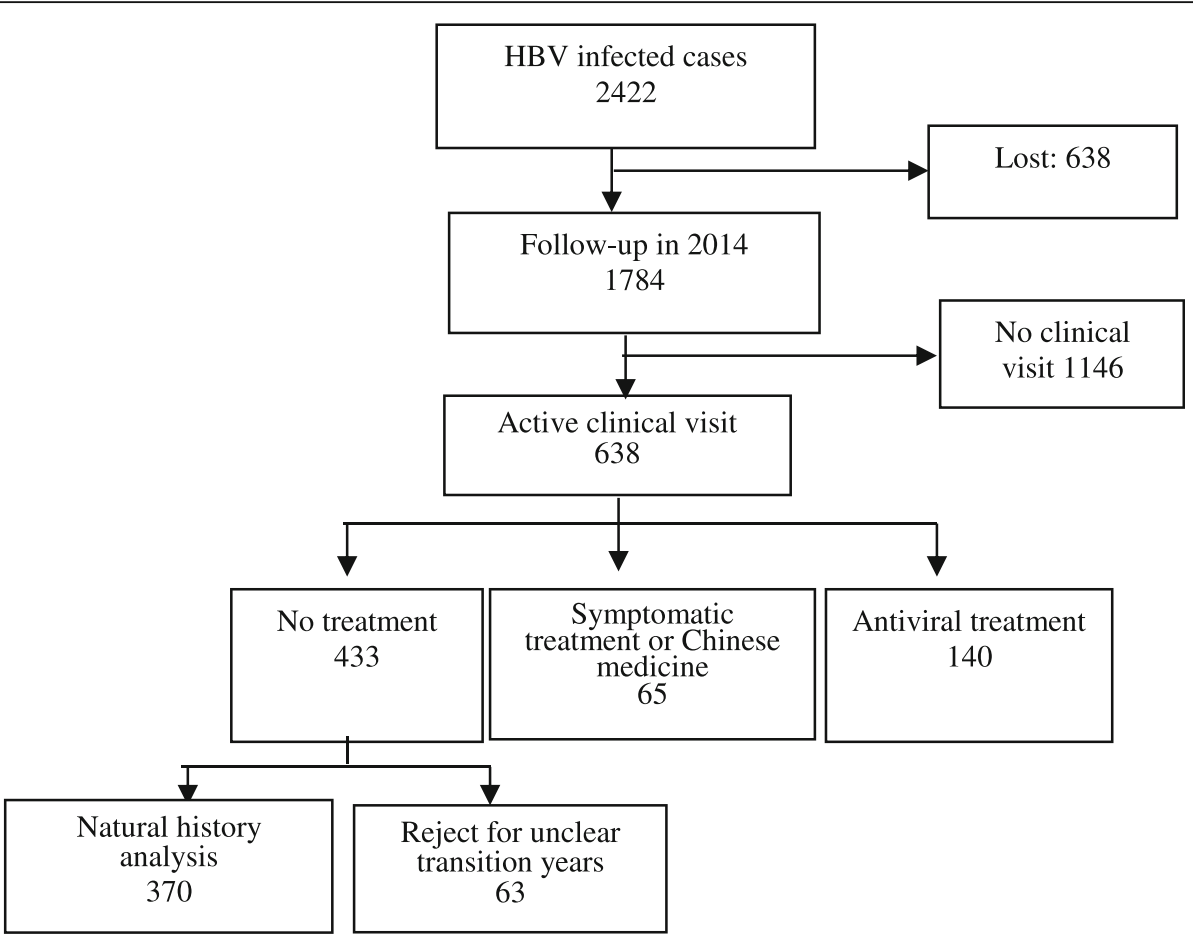

Fig. 2 Chronic HBV-infected people enrolled and cohort followed-up, China, 2009-2014.

because they are subject to higher risks of developing LC and HCC compared with young persons without medical intervention [29]. Previous studies have demonstrated that the health care knowledge on hepatitis B is poor among elderly people, and their limited or incorrect knowledge of hepatitis B results in negative medical behaviors [36, 37]. However, we also determined that although the proportion of young people seeking medical treatment was higher, the proportion of young people who received antiviral treatment was very low,

Table 2 The active medical care-seeking behaviors and treatment situations among chronic HBV-infected persons, China, 2009-2014

\begin{tabular}{|c|c|c|c|c|c|c|c|c|}
\hline \multirow[t]{3}{*}{ Medical activities } & \multirow{3}{*}{$\begin{array}{l}\text { Disease } \\
\text { status }\end{array}$} & \multirow{3}{*}{$\begin{array}{l}\text { Sample } \\
\text { Size }\end{array}$} & \multicolumn{6}{|c|}{ Treatment category } \\
\hline & & & \multicolumn{2}{|c|}{ No treatment } & \multicolumn{2}{|c|}{ Symptomatic treatment or Chinese medicine } & \multicolumn{2}{|c|}{ Antiviral treatmen } \\
\hline & & & $n$ & $\%$ & $\mathrm{n}$ & $\%$ & $\mathrm{n}$ & $\%$ \\
\hline \multirow[t]{4}{*}{ No clinical visit } & Carriers & 773 & 773 & 100 & - & - & - & - \\
\hline & $\mathrm{CHB}^{\mathrm{a}}$ & 361 & 361 & 100 & - & - & - & - \\
\hline & $L C^{b}$ & 12 & 12 & 100 & - & - & - & - \\
\hline & Sub-total & 1146 & 1146 & 100 & & & & \\
\hline \multirow[t]{5}{*}{ Active clinical visit } & Carriers & 408 & 289 & 70.8 & 30 & 7.4 & 89 & 21.8 \\
\hline & $\mathrm{CHB}$ & 216 & 137 & 63.4 & 33 & 15.3 & 46 & 21.3 \\
\hline & LC & 12 & 7 & 58.3 & 0 & 0.0 & 5 & 41.7 \\
\hline & $\mathrm{HCC}^{\mathrm{C}}$ & 2 & 0 & 0.0 & 2 & 100.0 & 0 & 0.0 \\
\hline & Sub-total & 638 & 433 & 67.9 & 65 & 10.2 & 140 & 21.9 \\
\hline \multirow[t]{5}{*}{ Total } & Carriers & 1181 & 1062 & 89.9 & 30 & 2.5 & 89 & 7.5 \\
\hline & $\mathrm{CHB}$ & 577 & 498 & 86.3 & 33 & 5.7 & 46 & 8.0 \\
\hline & LC & 24 & 19 & 79.2 & 0 & 0.0 & 5 & 20.8 \\
\hline & $\mathrm{HCC}$ & 2 & 0 & 0.0 & 2 & 100.0 & 0 & 0.0 \\
\hline & Sub-total & 1784 & 1579 & 88.5 & 65 & 3.6 & 140 & 7.8 \\
\hline
\end{tabular}

${ }^{a} \mathrm{CHB}$ chronic hepatitis $\mathrm{B}$

${ }^{b} L C$ liver cirrhosis

c HCC hepatocellular carcinoma 
Table 3 The risk factors associated with the active medical care-seeking behaviors and antiviral treatments in chronic HBV-infected persons, China, 2009-2014

\begin{tabular}{|c|c|c|c|c|c|c|c|c|c|c|}
\hline & \multirow{3}{*}{$\begin{array}{l}\text { Sample } \\
\text { size }\end{array}$} & \multicolumn{4}{|c|}{ Active clinical visit } & \multirow{3}{*}{$\begin{array}{l}\text { Sample } \\
\text { size }\end{array}$} & \multicolumn{4}{|c|}{ Antiviral treatment } \\
\hline & & \multicolumn{2}{|c|}{ Crude analysis } & \multicolumn{2}{|c|}{ Multivariable analysis } & & \multicolumn{2}{|c|}{ Crude analysis } & \multicolumn{2}{|c|}{ Multivariable analysis } \\
\hline & & $n$ & $P$-Value & $\operatorname{aRR}(95 \% \mathrm{Cl})$ & $P$-Value & & $n$ & $P$-Value & aRR $(95 \%(l) C l)$ & $P$-Value \\
\hline \multicolumn{11}{|l|}{ Region } \\
\hline East & 820 & 266 & 0.03 & $0.78(0.61-1.01)$ & 0.06 & 266 & 56 & 0.12 & & \\
\hline Central & 554 & 216 & & $1.02(0.87-1.34)$ & 0.88 & 216 & 57 & & - & - \\
\hline West & 410 & 156 & & 1 & & 156 & 28 & & & \\
\hline \multicolumn{11}{|l|}{ Rural/Urban } \\
\hline Urban & 688 & 275 & 0.004 & $1.3(1.0-1.6)$ & 0.04 & 275 & 62 & 0.77 & - & - \\
\hline Rural & 1096 & 363 & & 1 & & 363 & 78 & & & \\
\hline \multicolumn{11}{|l|}{ Gender } \\
\hline Male & 967 & 341 & 0.66 & - & - & 341 & 73 & 0.77 & - & - \\
\hline Female & 817 & 297 & & - & - & 297 & 67 & & & \\
\hline \multicolumn{11}{|l|}{ Beginning age-group } \\
\hline 0-19 & 266 & 90 & $<0.001$ & $1.5(1.1-2.1)$ & 0.017 & 90 & 20 & 0.004 & $0.7(0.4-1.3)$ & 0.20 \\
\hline $20-39$ & 588 & 261 & & $2.2(1.7-3.0)$ & $<0.001$ & 261 & 40 & & $0.4(0.3-0.7)$ & 0.001 \\
\hline $40-49$ & 510 & 178 & & $1.5(1.1-2.0)$ & 0.007 & 178 & 47 & & $0.8(0.5-1.4)$ & 0.44 \\
\hline $50-62$ & 420 & 109 & & 1 & & 109 & 33 & & 1 & \\
\hline \multicolumn{11}{|l|}{ Insurance type } \\
\hline URBMI ${ }^{\mathrm{a}}$ or $\mathrm{CHI} \mathrm{b}^{\mathrm{b}}$ & 320 & 146 & $<0.001$ & $2.5(1.7-3.6)$ & $<0.001$ & 146 & 34 & 0.04 & $2.6(1.1-6.3)$ & 0.04 \\
\hline $\mathrm{NRCMS}^{\mathrm{C}}$ & 1175 & 424 & & $1.9(1.4-2.6)$ & $<0.001$ & 424 & 99 & & $3.0(1.3-6.9)$ & 0.01 \\
\hline None or unclear & 289 & 68 & & 1 & & 68 & 7 & & 1 & \\
\hline \multicolumn{11}{|l|}{ Hospital level } \\
\hline Prefecture and above & - & - & - & - & - & 294 & 82 & 0.003 & $2.0(1.4-3.0)$ & $<0.001$ \\
\hline County and below & - & - & & & & 344 & 58 & & 1 & \\
\hline Total & 1784 & 638 & - & & & 638 & 140 & - & & \\
\hline
\end{tabular}

${ }^{\mathrm{a}}$ URBMI Urban residents' basic medical insurance, ${ }^{\mathrm{b}} \mathrm{CHI}$ Commercial health insurance, ${ }^{\mathrm{c}}$ NRCMS New Rural Cooperative Medical System

which is partly because some young HBV-infected cases do not meet antiviral indications. However, the lack of antiviral treatment was largely because young patients, especially those under the age of 30 , felt asymptomatic and did not take medication. In addition, we determined that the rural population had a lower rate of active medical care-seeking behavior compared with those living in urban areas, which may explain why we showed rural persons to be more vulnerable, having serious consequences of $60 \%$ LC and 100\% HCC rates diagnosed in rural areas at the beginning of this study. These results suggest that we should pay more attention to the education and management of HBV-infected people aged over 40 years, especially those in the rural areas.

We also determined that the type of insurance affects people's medical care-seeking behaviors. Those without

Table 4 The disease progress at the 5-year follow-up, China, 2009-2014

\begin{tabular}{|c|c|c|c|c|c|c|c|c|c|c|c|}
\hline \multirow{3}{*}{$\begin{array}{l}\text { Initial } \\
\text { diagnosis }\end{array}$} & \multirow{3}{*}{$\begin{array}{l}\text { Person- } \\
\text { years }\end{array}$} & \multicolumn{10}{|c|}{ Follow-up diagnosis } \\
\hline & & \multicolumn{2}{|c|}{ HBsAg sero-clearance } & \multicolumn{2}{|c|}{ Carriers } & \multicolumn{2}{|c|}{$\mathrm{CHB}^{\mathrm{a}}$} & \multicolumn{2}{|c|}{$\mathrm{LC}^{\mathrm{b}}$} & \multicolumn{2}{|c|}{$\mathrm{HCC}^{\mathrm{C}}$} \\
\hline & & $n$ & Annual rate (\%) & $\mathrm{n}$ & Annual rate (\%) & $\mathrm{n}$ & Annual rate (\%) & $n$ & Annual rate (\%) & $n$ & Annual rate (\%) \\
\hline Carriers & 821 & 11 & 1.3 & 185 & 22.5 & 56 & 6.8 & 0 & - & 0 & - \\
\hline $\mathrm{CHB}$ & 391 & 1 & 0.3 & 0 & - & 108 & - & 2 & 0.5 & 0 & - \\
\hline LC & 29 & 0 & - & 0 & - & 0 & - & 5 & 17.2 & 2 & 6.9 \\
\hline Total & 1212 & 12 & 1.0 & 185 & 15.3 & 164 & 4.6 & 7 & 0.6 & 2 & 0.2 \\
\hline
\end{tabular}

${ }^{a} \mathrm{CHB}$ chronic hepatitis $\mathrm{B}$

${ }^{b} L C$ liver cirrhosis

c HCC hepatocellular carcinoma 
insurance exhibited a lower active clinic visitation rate and antiviral treatment rate compared with those who were insured. This phenomenon reflects the huge economic burden of hepatitis B treatment. In China, nearly $70 \%$ of CHB patients' per capita annual income was lower than $\$ 1500$, and for $90 \%$ of them the cost of hepatitis B testing and treatment was unaffordable. For example, the monthly cost of the antiviral drug tenofovir (TDF), which is used to treat hepatitis B, was reduced greatly from $\$ 220$ to $\$ 70$ in 2016 [38], but this cost is still 4 times the price for the same dosage for HIV antiviral treatment ( $\$ 17 /$ month). The policies regarding reimbursement for hepatitis B antiviral drugs varied across the different insurance types and from province to province, ranging from nearly $\$ 300$ to $\$ 3000$ for URBMI (which primarily covered the urban population normally with higher reimbursement than NRCMS) or CHI (the applicant purchases commercial insurance from an insurance company at his own expense according to his personal economic ability and willingness). For the people covered by NRCMS, who were mostly in rural areas, the reimbursement rate was the lowest among these three types of insurance. This phenomenon may also be one of the reasons why the treatment rate is lower among patients who went to the prefecture or higher level hospitals compared with those who went to county or lower level hospitals, as we demonstrated in this study. We expect that if the antiviral treatment price declines, treatment coverage will rise.

Several limitations exist in this study. Firstly, the sample sizes are small, and the follow-up time is 5 years, both of which may affect the results. Secondly, we determined that $26 \%$ of the cohort dropped out in 2014, which may overestimate or underestimate the rate of self-motivated medical treatment seeking. Thirdly, there may be some recall bias in our study.

\section{Conclusion}

We identified that the proportions of the carriers and $\mathrm{CHB}$ among chronic HBV-infected persons in China were 64 and $35 \%$, respectively. The rate of selfmotivated seeking of antiviral treatment was lower, with only one-third of these community-based participants making active clinic visits and $8 \%$ taking antiviral therapy. The risk factors for failing to seek medical treatment included age greater than 40, low insurance reimbursement and residence in a rural area. Among the persons without medical intervention, only $1.0 \%$ exhibited HBsAg sero-clearance annually, and the progression from cirrhosis to HCC was rapid at an annual rate of $7 \%$.

\section{Abbreviations}

95\% Cl: 95\% Confidence interval; AFP: Alpha fetoprotein; ALT: Alanine transaminase; CHB: Chronic hepatitis B; CHI: Commercial health insurance;
CT: Computerized tomography; HBV: Hepatitis B virus; HCC: Hepatocellular carcinoma; HCV: Hepatitis C virus; HDV: Hepatitis D virus; LC: Liver cirrhosis; LTFU: Lost to follow-up; MRI: Magnetic Resonance Imaging; NRCMS: New Rural Cooperative Medical System; RR: Relative risk; TDF: Tenofovir;

URBMI: Urban residents' basic medical insurance

\section{Acknowledgements}

We would like to express our thanks to all the staff who contributed to the field work.

\section{Authors' contributions}

Conceived and designed the study: LXF, CFQ. Collected the data: ZH, ZGM, WFZ, YZD, MN, SXJ. Analyzed and interpreted the data: ZH, ZGM, WFZ. Wrote the first draft of the manuscript: ZH. Supervised the study: LXF and CFQ. All authors were involved in revising the article critically for important

intellectual content, and all authors had read and approved the final version of the manuscript.

\section{Funding}

The study design, cohort building and follow-up, data collection and analysis of this research was funded by the Chinese Ministry of Science and Technology Program for Important Infectious Diseases Control and Prevention (2012ZX10002001, 2017ZX10105015). The funding body was not involved in the design of the study or in collection or analysis of the data.

\section{Availability of data and materials}

Because of data protection, the data generated and analyzed during the current study are not published, but the appropriate authors may obtain access to and/or analyze the data from the current study upon reasonable request.

\section{Ethics approval and consent to participate}

The ethics approval for this study was signed by the China CDC Ethical Review Committee (Ethics certificate:201339), and the study was conducted following the ethics regulations. Cohort participants were informed of the study purpose and their right to keep information confidential. Before the investigation, an informed consent form was signed by all participants.

\section{Consent for publication}

Not applicable

\section{Competing interests}

The authors declare that they have no competing interests.

Received: 25 September 2018 Accepted: 29 May 2019

Published online: 08 July 2019

\section{References}

1. World Health Organization. Global hepatitis report 2017. Geneva: World Health Organization; 2017.

2. Niederau C. Chronic hepatitis B in 2014: great therapeutic progress, large diagnostic deficit. World J Gastroenterol. 2014;20(33):11595-617.

3. Zhang Z, Chen C, Li Z, Wu YH, Xiao XM. Individualized management of pregnant women with high hepatitis B virus DNA levels. World J Gastroenterol. 2014;20(34):12056-61.

4. World Health Organization. Global health sector strategy on viral hepatitis 2016-2021. Geneva, Switzerland: World Health Organization; 2016.

5. Papatheodoridis GV, Lampertico P, Manolakopoulos S, Lok A. Incidence of hepatocellular carcinoma in chronic hepatitis B patients receiving nucleos(t)ide therapy: a systematic review. J Hepatol. 2010;53(2):348-56.

6. Chen XX, Cheng JW, Huang A, Zhang X, Wang J, Fan J, et al. Onco Targets Ther 2017; 10: 5363-5375.

7. Papatheodoridis GV, Chan HL, Hansen BE, Janssen HL, Lampertico P. Risk of hepatocellular carcinoma in chronic hepatitis B: assessment and modification with current antiviral therapy. J Hepatol. 2015;62(4):956-67.

8. Sarin SK, Kumar M, Lau GK, Abbas Z, Chan HL, Chen CJ, et al. Asian-Pacific clinical practice guidelines on the management of hepatitis B: a 2015 update. Hepatol Int. 2016;10(1):1-98.

9. Cui F, Shen L, Li L, Wang H, Wang F, Bi S, et al. Prevention of chronic hepatitis B after 3 decades of escalating vaccination policy, China. Emerg Infect Dis. 2017;23(5):765-72. 
10. Liang XF, Bi SL, Yang WZ, et al. Evaluation of the impact of hepatitis B vaccination among children born during 1992-2005 in China. J Infect Dis. 2009;200(1):39-47.

11. Ministry of Health. Chinese Center for Disease Control and Prevention. In: The National Report of hepatitis B Sero-survey in China. Beijing: People's medical publishing house; 2010.

12. Chen W, Zheng R, Baade PD, Zhang S, Zeng H, Bray F, et al. Cancer statistics in China, 2015. CA Cancer J Clin. 2016;66(2):115-32.

13. De Martel C, Maucort-Boulch D, Plummer M, Franceschi S. World-wide relative contribution of hepatitis $B$ and $C$ viruses in hepatocellular carcinoma. Hepatology. 2015;62(4):1190-200

14. Wang FS, Fan JG, Zhang Z, Gao B, Wang HY. The global burden of liver disease: the major impact of China. Hepatology. 2014;60(6):2099-108.

15. Qu ZY. Epidemiological study on the distribution of surface antigen and surface antibody of hepatitis B virus in China. J Chin Microbiol Immunol. 1986;6(Suppl:20-40.

16. Zhu SS, Dong Y, Wang LM, Xu ZQ, Chen DW, Gan Y, et al. A retrospective study on the liver pathological characteristics and the effect of antiviral treatment for 1 to 7 years old children with heptitis B e antigen negative chronic hepatitis B. Chin J Pediatr. 2016;54(8):587-91.

17. Li ZQ, Hu CL, Yu P, Gu XY, Zhang JJ, Li H, et al. The development of hepatocarcinoma after long-term antivirus treatment of Chinese patients with chronic hepatitis B virus infection: incidence, long-term outcomes and predictive factors. Clin Res Hepatol Gastroenterol. 2017;41(3):311-8.

18. Xu Y, Zhang YG, Wang X, Qi WQ, Qin SY, Liu ZH, et al. Long-term antiviral efficacy of entecavir and liver histology improvement in Chinese patients with hepatitis B virus-related cirrhosis. World J Gastroenterol. 2015;21(25): 7869-76.

19. Wu YZ, Zhao FL, Zhang CZ, Li MH, Xie Y. Factors related to the outcome of patients with chronic severe hepatitis $B$ and effectiveness of antivirus therapy. Chin J Exp Clin Virol. 2007;21(2):120-2.

20. Ministry of Health. Diagnostic criteria for viral hepatitis B (WS299-2008). 2008.

21. Chinese Society of Hepatology. Chinese Medical Association; Chinese Society of Infectious Diseases, Chinese Medical Association. The guideline of prevention and treatment for chronic hepatitis B, a 2015 update. Zhong Hua Gan Zang Bing Za Zhi. 2015:23(12):888-905.

22. Zheng $X$, Wang J, Yang D. Antiviral therapy for chronic hepatitis B in China. Med Microbiol Immunol. 2015;204(1):115-20.

23. Zheng H, Wang FZ, Zhang GM, Wu ZH, Miao N, Sun XJ, et al. Study on health-seeking behavior and influencing factors among Chinese hepatitis $B$ surface antigen positive adults. Chin J Epidemiol. 2016;37(4):455-9.

24. Zhuang $\mathrm{H}$. To improve the accessibility of hepatitis B treatment. J of Clin Hepatol. 2016;24(6):1031-2.

25. Jiang SZ, Lu FM, Zhuang $H$. The clinical significance of quantitative detection of HBV DNA in the chronic infected patients. Chin J Lab Med. 2012;35(2):117-21.

26. Lu FM, Zhuang H. Management of hepatitis B in China. Chin Med J. 2009; 122(1):3-4.

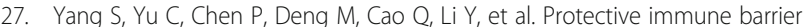
against hepatitis $B$ is needed in individuals born before infant HBV vaccination program in China. Sci Rep. 2015;5(1):18334-43.

28. Chu CM, Liaw YF. HBsAg sero-clearance in asymptomatic carriers of high endemic areas: appreciably high rates during a long-term follow-up. Hepatology. 2007:45(5):1187-92.

29. Hou JL, Wang GQ, Wang FS, Cheng J, Ren H, Zhuang H, et al. Guideline of prevention and treatment for chronic hepatitis B (2015 update). J Clin Transl Hepatol. 2017:5(4):297-318

30. Zhang LP, Zeng XZ, Zhao LJ, Yue JR. Study on impact factors of hepatitis $B$ patients medical behaviors in Shenzhen. Chin J Mod Nurs. 2008;14(29): 3103-4.

31. Zheng $H$, Wang FZ, Zhuang GH, Zhang GM, Chen YS, Gong XH, et al. Quality of life among chronic hepatitis B virus infected people in their communities. Chin J Vaccin Immunization. 2014;20(4):309-13.

32. Wang $P$, Li JW, Pan X, Wang LD, Wu GH. Investigation and analysis of hepatitis $b$ disease cognition and discrimination. J Nurses Training. 2013; 28(17):1570-2

33. Wang FY, Tang XD, Zhang YQ, Lin M, Liu G, Liu YL, et al. Investigation and analysis of factors for the quality of life in patients with chronic hepatitis $B$. Chin J Gastroenterol Hepatol. 2010;19(5):404-7.

34. Zhuang $\mathrm{H}$. Strengthen the antiviral therapy for chronic hepatitis B. Chin J Exp Clin Virol. 2007;22(2):101.
35. World Health Organization. Regional Office for the Western Pacific. In: WHO technical consultation on a comprehensive National Hepatitis Programme in China with a focus on viral hepatitis B and C treatment, Beijing, China, 21 February 2014: meeting report. Manila: WHO Regional Office for the Western Pacific; 2014.

36. Liu J. The investigation and analysis of knowledge of standard treatment and liver cancer among hepatitis B patients. Med Aesthetics Cosmetol. 2013;3(3):254-5

37. Pan XJ, Zheng M, Tu QF, Liu W. Knowledge of hepatis B among rural residents in Jiangxi province. Chin J Public Health. 2012;28(3):291-3.

38. http://www.nhc.gov.cn/yaozs/s3578/201605/ 168187d0028a44e0bbfb0be35d2d8c33.shtml. Accessed 22 Feb 2018.

\section{Publisher's Note}

Springer Nature remains neutral with regard to jurisdictional claims in published maps and institutional affiliations.
Ready to submit your research? Choose BMC and benefit from:

- fast, convenient online submission

- thorough peer review by experienced researchers in your field

- rapid publication on acceptance

- support for research data, including large and complex data types

- gold Open Access which fosters wider collaboration and increased citations

- maximum visibility for your research: over $100 \mathrm{M}$ website views per year

At BMC, research is always in progress.

Learn more biomedcentral.com/submissions 